Conflitos ambientais: uma análise da assimetria de poder entre os atores sociais envolvidos no caso do Mineroduto da Ferrous Dayane Rouse Neves Sousa, Marcelo Leles Romarco de Oliveira, Bruno Costa da Fonseca

\title{
CONFLITOS AMBIENTAIS: UMA ANÁLISE DA ASSIMETRIA DE PODER ENTRE OS ATORES SOCIAIS ENVOLVIDOS NO CASO DO MINERODUTO DA FERROUS
}

\section{Environmental conflict: an analysis of power asymmetry between social actors involved in the case of Ferrous Pipeline}

\author{
Dayane Rouse Neves Sousa \\ Universidade Federal de Viçosa, Viçosa, Minas Gerais, Brasil \\ sousadayane@ymail.com \\ Marcelo Leles Romarco de Oliveira \\ Universidade Federal de Viçosa, Viçosa, Minas Gerais, Brasil \\ marceloromarco@gmail.com \\ Bruno Costa da Fonseca \\ Universidade Federal de Viçosa, Viçosa, Minas Gerais, Brasil \\ bruno_fonsecacosta@hotmail.com
}

Artigo recebido em 16/10/2013 e aceito para publicação em 18/11/2015

RESUMO: Este trabalho intenta apresentar o conflito ambiental instaurado em razão da instalação do mineroduto da Ferrous Ressources S/A, na microrregião de Viçosa-MG, construindo uma análise do posicionamento dos principais atores sociais envolvidos, assim como suas respectivas relações de poderes. O mineroduto da Ferrous ligará o complexo da Mina da Viga, em Congonhas-MG, ao porto da Ferrous Ressources, em Presidente Kennedy-ES, com o intuito de exportar minério de ferro. Para tanto, foram utilizados, como procedimentos metodológicos: pesquisas bibliográficas; análise documental; entrevistas semiestruturadas com diferentes atores; e acompanhamento de reuniões populares da Campanha pelas Águas e Contra o Mineroduto da Ferrous, das audiências públicas e das manifestações populares acontecidas na microrregião de Viçosa. Além disso, houve acompanhamento da discussão do mineroduto em jornais locais e em blogs. Com isso, este trabalho demonstrou que a empresa Ferrous, detentora de alto poder econômico e simbólico, assume o papel de dominadora no conflito. Por outro lado, os atingidos e os movimentos sociais contrários à construção do empreendimento, por vezes, estão no papel de dominados, restandolhes articular estratégias de resistência para adiar/barrar a construção do mineroduto. O Estado, por sua vez, assume diferentes papéis nesse contexto, demonstrando, com isso, fragilidade na intermediação e gestão do conflito instaurado pelo mineroduto da Ferrous, principalmente, na microrregião de ViçosaMG.

Palavras-chaves: Conflito ambiental; Atores sociais; Mineroduto.

ABSTRACT: This work intends to present the environmental conflict initiated due to the installation of pipeline Ferrous Ressources S / A, in the micro region of Viçosa-MG, building an analysis of the positioning of the main 
social actors involved, as well as their respective relations of power. Thepipeline of Ferrous will connect the complex Beam Mine in Congonhas-MG, the port of Ferrous Ressources in Presidente Kennedy-ES in order to export iron ore. To do so, were used as methodological procedures: bibliographical research; document analysis; semi-structured interviews with different actors; and follow-up meetings of the Popular Campaign Against the Water and Pipeline Ferrous, public hearings and demonstrations taken place in the Viçosa. Furthermore, there was monitoring of the pipeline discussion in local newspapers and on blogs. Thus, this study demonstrated that the Ferrous company, which owns high economic and symbolic power, assumes the role of dominating the conflict. On the other hand, those affected and social movements against the construction of the project, are sometimes in the role of dominated, leaving them to articulate strategies of resistance to delay / stop the construction of the pipeline. The state, in turn, assumes different roles in this context, demonstrating thereby weakness in mediation and conflict management established by pipeline Ferrous mainly in the micro region of Viçosa-MG.

Keywords: Environmental conflict; Social actors; Pipeline.

\section{INTRODUÇÃO}

A sociedade na qual vivemos hoje sofreu, ao longo dos anos, diversas transformações em suas estruturas políticas, sociais e econômicas. A dita "modernização" trouxe consigo diversas práticas que podem ser encaradas como boas ou ruins, de acordo com pontos de vistas distintos. Contudo, o que se vê, de um modo geral, é que as melhorias nas condições e no padrão de vida de alguns sujeitos e grupos sociais têm sido à custa de outros. É fácil verificar esta afirmativa quando nos deparamos com os tipos de relações sociais vivenciadas no Brasil - desde a época de sua colonização -, sobretudo, no que diz respeito aos usos e apropriação dos recursos naturais de nosso território.

Nesse sentido, tem ocorrido uma apropriação privada dos recursos naturais em prol do "desenvolvimento" e da acumulação de capital por grandes empresas nacionais e estrangeiras. Não obstante a isso, há de se ressaltar que, na mesma proporção, têm acrescido impactos sociais e ambientais que atingem, principalmente, grupos sociais marginalizados e menos destituídos de capital econômico, como é caso das famílias ribeirinhas, quilombolas, agricultores familiares, indígenas, entre outros. Assim, este tipo de tensão cria uma aguda assimetria de poderes entre os atores sociais envolvidos, colocando-os em posições antagônicas que, por sua vez, cria uma relação de dominantes e dominados. Via de regra, o ator social dominante possui capital econômico e simbólico diferenciado dos demais envolvidos. No entanto, isso não limita as estratégias de resistência firmadas pelos outros atores. Destarte, este tipo de contexto provoca o que chamamos, aqui, de conflitos ambientais, que acontece, mormente, quando existe uma disputa pelos direitos dos usos de um determinado território.

Para exemplificar este tipo de relação conflituosa e de poderes assimétricos, trazemos, neste trabalho, o emblemático caso do mineroduto da Ferrous Ressources S/A, que consiste num projeto de capital norte-americano, australiano e inglês. A construção do mineroduto tem por intento levar minério de ferro do complexo da Mina da Viga, em Congonhas-MG, ao porto da Ferrous Ressources, em Presidente Kennedy-ES, atravessando 22 municípios entre os Estados de Minas Gerais, Rio de Janeiro e Espírito Santo.

Portanto, o projeto de implantação do mineroduto da Ferrous pode ser considerado um potencializador de conflitos ambientais, pois os interesses de cada ator envolvido (empreendedor, Estado, atingidos pelo mineroduto e sociedade em geral, representada pelos movimentos sociais) são diferentes em relação à percepção dos usos atribuídos ao território no qual o mineroduto provavelmente irá passar. Por isso, torna-se importante estudar os atores sociais envolvidos, assim como as estruturas de poder e os reais interesses por trás deste conflito.

Nesse sentido, este trabalho intenta apresentar o conflito ambiental instaurado em razão 
da instalação do mineroduto da Ferrous Ressources S/A, na microrregião de Viçosa-MG, construindo uma análise do posicionamento dos principais atores sociais envolvidos, assim como suas respectivas relações de poderes. Para tanto, foram utilizados, como procedimentos metodológicos: pesquisas bibliográficas; análise documental; entrevistas semiestruturadas com diferentes atores; acompanhamento de reuniões populares da Campanha pelas Águas e Contra o Mineroduto da Ferrous, das audiências públicas e das manifestações populares acontecidas na microrregião de Viçosa; e, por fim, através da transcrição das entrevistas e da sistematização dos demais dados, foram realizadas as inferências para alcançar os objetivos proposto neste trabalho. Além disso, houve acompanhamento da discussão do mineroduto em jornais locais e em blogs, sobretudo, no Viçosa Cidade Aberta e no da Campanha pelas Águas e Contra o Mineroduto da Ferrous.

\section{CONFLITOS AMBIENTAIS, ATORES SOCIAIS E ASSIMETRIA DE PODERES}

Pereira (2010 apud DEUTSCH, 1973) argumenta que os conflitos ambientais tendem a se manifestar nas sociedades quando uma ação humana interfere ou impede o aparecimento de outra atividade que seja inconciliável com a primeira. Os conflitos podem aparecer em forma de manifesto ou ocultos, isto é, o primeiro é caracterizado como um conflito visível para os atores sociais envolvidos no embate e o segundo é designado como um conflito impercebível aos olhos de alguns atores sociais, caracterizando-se como um conflito latente.

Para Araújo (2008), os conflitos são representações da complexidade das estruturas de uma sociedade e, conforme o grau da complexidade, maiores são as suas dificuldades de resoluções e demandam estudos mais aprofundados e eficientes para soluciona-los. Portanto, cada conflito está em um determinado território com seus atores sociais e suas particularidades, enaltecendo que não há uma receita para ser aplicada na solução de um determinado embate, porque estes são diferentes um dos outros.

Nessa perspectiva, Santos (2012) enfatiza que, ao estudar os conflitos ambientais, é necessário entender que sociedade e meio ambiente são realidades indissociáveis, visto que os elementos que compõem o ambiente (biomas florestais, solos, recursos hídricos e minerais, dentre outros) contêm significados históricos, simbólicos e culturais que influenciam diretamente a configuração de como os diversos segmentos sociais encaram e fazem uso dos mesmos. Ainda segundo a autora, os atores sociais veem os recursos naturais de modo diferente e jamais serão os mesmos para cada ator.

Neste mesmo sentido, Acselrad (2004) enfatiza que o meio ambiente é uma estrutura composta por territórios e recursos naturais, atrelados aos sentimentos socioculturais, que retratam os interesses distintos de cada ator social. Assim, os conflitos ambientais afloram quando há ameaça na estrutura espacial do território e/ou dos recursos naturais ocasionada por atividades originadas pelos atores sociais.

A identificação dos atores sociais e das relações conflituosas entre eles se tornam um ponto importante para entender o conflito instaurado neste trabalho. Os atores, geralmente representados por indivíduos, grupos, organizações ou Estados, possuem identidade própria, reconhecimento social e capacidade de modificar o contexto no qual estão inseridos. Vargas (2007) elenca alguns aspectos que devem ser levados em consideração:

a) Os atores sociais apresentam diferentes níveis de conhecimento e informação. É nítido que empresários e representantes do Governo possuem possibilidade de maior acesso às informações e conhecimentos do que povos indígenas e camponeses, por exemplo;

b) Existe uma grande diferença entre os atores no que tange à apropriação dos recursos e de poderes (expresso em termos políticos, econômicos e sociais). Nesse sentido, Bredariol (2001) nos remonta ao fato de que a existência de um conflito pode resultar em insegurança por parte dos empreendedores quanto à viabilidade dos poderes de decisão e controle;

c) Via de regra, existem diferenças 
consubstanciais quanto aos aspectos culturais, tendo em vista que cada grupo social tem uma forma de relação e apropriação dos recursos naturais.

É importante corroborar que a análise dos atores sociais envolvidos em um embate se torna completa quando é feito o mapeamento das intenções e das posições destes. Nascimento e Bursztyn (2010, p. 71-72) ratificam que "em um conflito socioambiental, as interações políticas são muitas e, consequentemente, as mudanças de posicionamento de alguns atores envolvidos no conflito não são raras". Assim sendo, para se tentar entender como se dão os embates, é importante percebermos como se configuram as assimetrias de poderes entre os atores. Segundo Brumer e Santos (2006), existe uma desigualdade social e uma assimetria de poder entre as classes, os grupos sociais, ou daqueles que, de alguma forma, se utilizam dos recursos de algum espaço. Para Vargas (2007), os recursos, na maior parte das vezes, são comuns em espaços sociais onde são estabelecidas relações complexas e desiguais entre distintos atores sociais - empresários rurais, agricultores familiares, minorias étnicas, agências do governo, entre outros. Portanto, aqueles atores com maior acesso ao poder são os que detêm o controle sobre o acesso e o uso dos recursos naturais.

Viana (2005) explana que, de um modo geral, a essência dos conflitos ambientais é caracterizada pela disputa de poder, como também é exposto por Santos (2012, p. 36).

O meio ambiente, como um terreno contestável material e simbolicamente, consiste em reconhecer, na verdade, que os conflitos ambientais se traduzem em relações de poder, através das quais os atores sociais, munidos de suas distintas formas de interagir com o meio ambiente, se enfrentam pelo domínio de um mesmo território ou de seus recursos naturais.

Nobert Elias (1970), em seus estudos sobre modelos de jogos, salientou as situações de conflitos e as assimetrias de poderes existentes. Não obstante, para ele, o poder não deve ser encarado somente como algo pessimista, causador de desigualdades nas sociedades - apesar de reconhecer este efeito inevitável. É preciso buscar um equilíbrio do poder inerente a todas as relações humanas. Pierre Bourdieu (1998), de forma mais específica, vai destacar, numa situação de disputa, o poder simbólico, por sua vez, fruto de um mecanismo de dominação maior, o qual só pode ser exercido com a cumplicidade daqueles que são dominados, ou, em outras palavras, o poder simbólico representa um "poder invisível que só pode ser exercido com a cumplicidade daqueles que não querem saber que lhe estão sujeitos ou mesmo que o exercem" (BOURDIEU, 1998, p. 7-8).

Max Weber (2000), ao retratar sobre os tipos de dominação, tem muito a contribuir para o entendimento dos conflitos e de como a parte que detém mais poder age sobre a outra, destituída de recursos. Weber, ao escolher trabalhar com a categoria de dominação, enfatiza que existe a possibilidade de um indivíduo obedecer perante a uma ordem que lhe foi dada e que, com efeito, este pode encarar tal fato como legítimo. Portanto, Weber elenca três tipos de dominação, a citar: dominação carismática, dominação tradicional e dominação racional-legal. A dominação carismática estaria ligada às qualidades pessoais de um indivíduo [místicas, por vezes], enquanto a dominação tradicional remeteria às tradições e aos costumes de uma dada sociedade. Contudo, o que nos importa dar maior ênfase, neste estudo, está na concepção de dominação racionallegal. A dominação racional-legal está pautada em regras e normas aos quais os dominados estão submetidos, sobretudo, em lugares onde prevalece a hierarquia de um cargo ou a elaboração de uma lei. Este conceito permite observar a ação do Estado e de suas instâncias burocráticas ao legitimar a implementação de um empreendimento através de um decreto de Utilidade Pública, por exemplo. Ou seja, a partir de então a dominação (e o exercício do poder) é feita através de um documento 'legal' e, com efeito, a desapropriação de terras se torna legítima.

Desta forma, estes conflitos estão sendo configurados a partir de uma perspectiva da relação de poder entre distintos segmentos sociais. Que seja através de interesses que estejam ligados a acessos de bens e serviços, tais como: disputa em termos de partido, esferas municipais, estaduais e federais de 
gerenciamento de recursos, empresariado, dentre outros. Ou da perspectiva que considere o conflito ambiental a partir de diferenças entre valores e representações simbólicas divergentes, tais como: a resistência de comunidades rurais, as ações de empreendedores, a inserção nos conflitos por grupos universitários, o posicionamento da Igreja Católica, a participação de agentes do Estado, entre outras.

\section{UMA BREVE DESCRIÇÃO SOBRE O MINERODUTO DA FERROUS}

A empresa Ferrous Ressources S/A, de capital norte-americano, australiano e inglês, está buscando implantar um Projeto de Mineroduto, com uma faixa de servidão de 100 metros de largura e 400 mil metros de comprimento, que ligará o complexo da Mina da Viga, em Congonhas-MG, ao porto da Ferrous Ressources, em Presidente Kennedy-ES. Este empreendimento percorrerá 22 municípios, sendo dezessete em Minas Gerais, três no Rio de Janeiro e dois no Espírito Santo, como pode ser visto na Figura 1.

Figura 1 - Localização do Mineroduto Ferrous desde o complexo da Mina da Viga, em Congonhas-MG, até ao porto da Ferrous Ressources, em Presidente Kennedy-ES

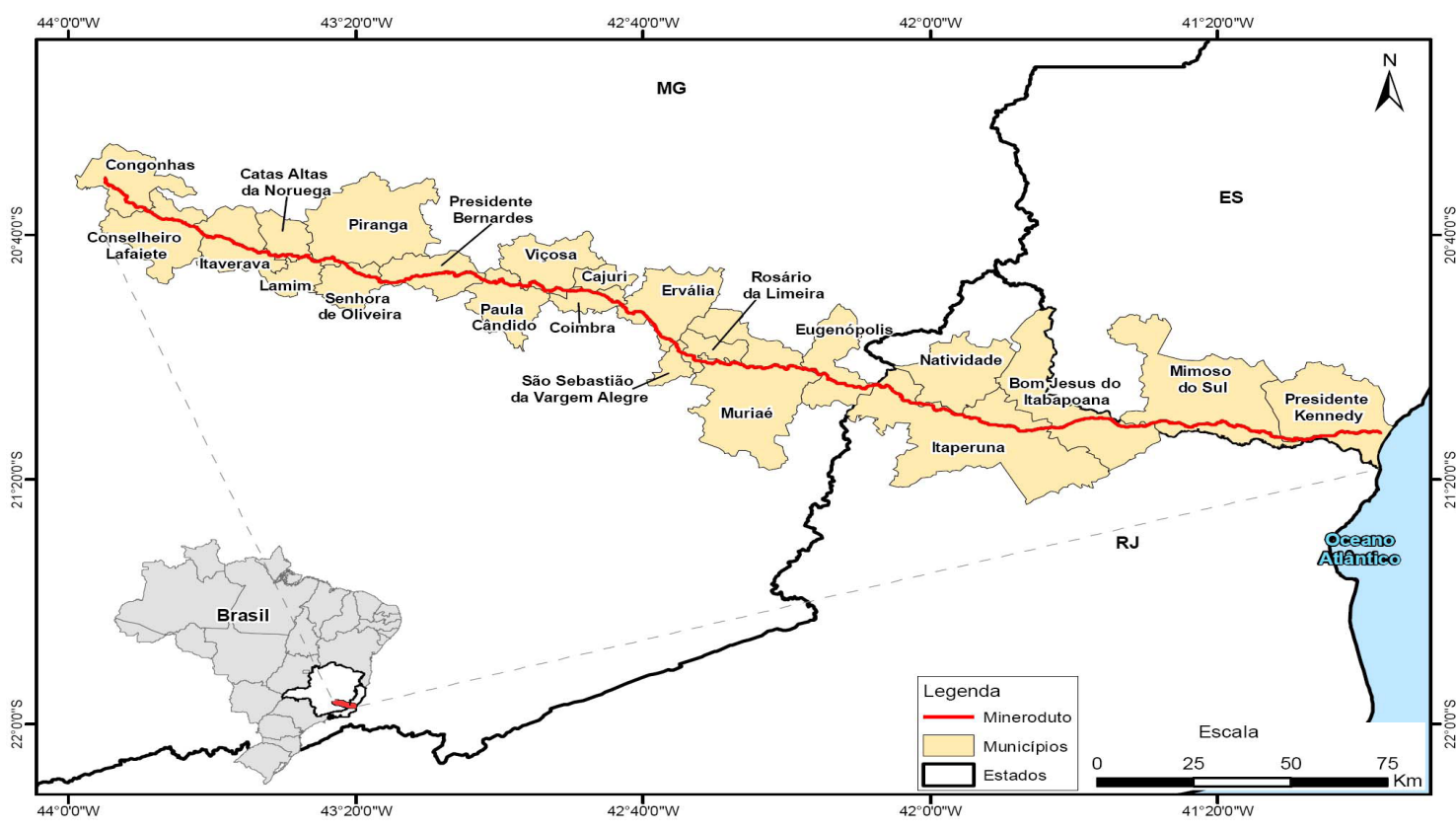

Fonte: Rima Ferrous - Minas Gerais, Rio de Janeiro e Espírito Santo (2010)

Nesse trabalho, o enfoque será dado somente para a microrregião de Viçosa-MG, que compõe os seguintes municípios: Viçosa, Cajuri, Ervália e Paula Cândido. Justifica a escolha desta área em razão de ser o local onde está ocorrendo maiores manifestações contrárias a tal empreendimento, o que culminou na criação de uma campanha denominada "Campanha pelas Águas e Contra o Mineroduto da Ferrous". Esta foi concebida a partir da organização de vários atores sociais atingidos pelo mineroduto da Ferrous e por representantes dos movimentos sociais, com o objetivo de promover espaços para discutir e informar os atingidos e à comunidade em geral sobre os impactos que poderão ser causados pelo mineroduto e, ainda, de criar mecanismos de resistência contra tal empreendimento.

No final de maio de 2013, a Ferrous solicitou a renovação da Licença Prévia, a primeira licença 
do processo, e ainda deu entrada nos papéis para a obtenção da Licença de Instalação, que garante à empresa o direito de começar as obras de construção do mineroduto. No entanto, até outubro de 2015, a Ferrous ainda não havia conseguido a Licença de Instalação fornecida pelo Instituto Brasileiro do Meio Ambiente e dos Recursos Naturais Renováveis (IBAMA).

De acordo com dados do Estudo de Impactos Ambientais (EIA) do Mineroduto da Ferrous (2010), 113.745 pessoas, inseridas no recorte espacial deste estudo, serão, diretamente e indiretamente, afetadas com a implantação do mineroduto da Ferrous nas diferentes fases de execução do projeto. $\mathrm{Na}$ fase da construção do mineroduto, estes contingentes terão que se deparar com barulhos de máquinas, com o aumento de poeira e com homens "estranhos" circulando em suas propriedades, o que incomodará essas pessoas. Também terão alguns problemas com a utilização de águas em suas propriedades, pois o trajeto do mineroduto afetará algumas nascentes, o que irá alterar, por sua vez, alguns rios e córregos. "Isto significa que o uso da água para beber, por exemplo, pode ser prejudicado, o que afetará alguns proprietários situados abaixo do ponto onde ocorrer tal alteração" (BRANDT, 2010, p. 50). Já na fase de operação as pessoas atingidas terão que conviver com o barulho da passagem do minério de ferro no mineroduto e com os impactos citados no parágrafo anterior, entretanto, estes, provavelmente, se tornarão menos intensos, mas ainda continuarão. Por fim, na fase de desativação do mineroduto, os mesmos impactos da implantação se repetirão (BRANDT, 2010).

Além disso, a implantação do mineroduto afetará áreas em que há vegetação típica do bioma da Mata Atlântica, incluindo as matas ciliares e de galeria, além de áreas de pastagens e áreas antropizadas. De acordo com os dados do EIA do Mineroduto da Ferrous (2010), a instalação do mineroduto representa o surgimento e a ampliação de processos erosivos e acúmulo de material inconsolidado nas drenagens, contribuindo, assim, para o assoreamento. Outrossim, irá implicar em desmate e, necessariamente, em grandes movimentações de terra, com abertura de valas para instalação de tubos, cortes de taludes, abertura de acessos, instauração de canteiro de obras e de depósito e faixa de manutenção.

\section{CONFLITOS AMBIENTAIS: UMA ANÁLISE DA ASSIMETRIA DE PODER ENTRE OS ATORES SOCIAIS ENVOLVIDOS NO CASO DO MINERODUTO DA FERROUS}

O surgimento do conflito ambiental na microrregião de Viçosa-MG se deu a partir da expectativa de implantação do mineroduto da Ferrous, pois a realização do empreendimento sem a devida discussão e consentimento dos atores sociais envolvidos, sobretudo dos atingidos, provocou tal embate. A partir daí, o conflito foi se desdobrando através do valor das indenizações da terra; do local da propriedade rural a ser desapropriado para a passagem do mineroduto; da falta de informações sobre a implantação do empreendimento; dos prejuízos econômicos e ambientais nas propriedades atingidas e, ainda, do problema da falta de água no município de Viçosa com a passagem do mineroduto nas nascentes do ribeirão São Bartolomeu, uma das principais fontes de abastecimento de água do município.

Sendo assim, serão apresentados, a seguir, os atores sociais envolvidos no embate e os seus posicionamentos, e será analisada a assimetria de poder entre os mesmos.

Atingidos pelo mineroduto da Ferrous: estes são agricultores familiares, proprietários de chácara e sitiantes. Eles afirmam que a implantação do mineroduto tem trazido desconfiança, preocupação e desgaste devido à falta de informações e/ou disseminação de informações desencontradas ocasionadas pela falta de comprometimento da empresa Ferrous e, principalmente, a baixa avaliação dos imóveis a serem desapropriados. Além disso,

[...] eles alegam que estão sendo injustiçados e que terão prejuízos econômicos e danos ambientais em suas propriedades causados pela instalação do mineroduto. Muitos produtores sobrevivem da agricultura familiar e outros da produção e comercialização de produtos agrícolas. Com o mineroduto, as propriedades correm o risco de não servirem mais para a 
produção de café, frutas cítricas e eucaliptos, por exemplo. Outra preocupação é em relação à região, que é cercada por montanhas e muitas propriedades, terá formulação de taludes (barranco), modificando a paisagem natural e prejudicando o valor comercial da mesma (JORNAL TRIBUNA LIVRE, 2011, p. 17).

Ademais, os atingidos reclamaram que o tempo para questionar os valores das indenizações é pequeno e, ainda, que as indenizações estão sendo abaixo do valor real das propriedades. Apesar de ter apresentado o posicionamento contra a implantação do mineroduto, foi possível perceber, na vivência em campo, que existem alguns atingidos, a minoria, se posicionando a favor do empreendimento, alegando que as indenizações pagas pela Ferrous estão justas e corretas. Além disso, constatamos que os proprietários das terras estão recebendo tratamento diferenciado na hora da negociação da sua propriedade. Houve um caso no qual o representante da Ferrous levou uma psicóloga até a casa de um dos atingidos para que este proprietário fosse convencido a receber o valor que a Ferrous propôs e que a cidade seria melhor do que o meio rural para morar, além de dizer que o dinheiro pago pela desapropriação daria para comprar um carro (RELATO DO ENTREVISTADO B, 2012).

Tendo em vista esta relação conflituosa entre o empreendedor e algumas comunidades atingidas, direta e indiretamente, por tal empreendimento, estas começaram a utilizar estratégias de resistência contra a implantação do mineroduto da Ferrous. Tais ações podem ser examinadas no Quadro 1 e na Figura 2.

Quadro 1 - Principais resistências mapeadas na microrregião de Viçosa-MG (2012-2015)

\begin{tabular}{|c|c|c|}
\hline Tipos de manifestações & Descrição dos objetivos do ato & Segmentos sociais interessados \\
\hline $\begin{array}{l}\text { Caminhada na Feira Livre } \\
\text { do Produtor Rural de Viçosa, } \\
\text { realizada em abril de } 2012 \text {. }\end{array}$ & $\begin{array}{l}\text { A caminhada tinha como objetivo } \\
\text { alertar a população viçosense sobre } \\
\text { os impactos ocasionados pela } \\
\text { possível instalação do mineroduto } \\
\text { da Ferrous na região. }\end{array}$ & $\begin{array}{l}\text { MAB (Movimento dos Atingidos } \\
\text { por Barragem), MST (Movimento } \\
\text { dos Trabalhadores Sem Terra), } \\
\text { PACAB (Projeto de Assessoria } \\
\text { das Comunidades Atingidas por } \\
\text { Barragens e Mineração, ENEBio } \\
\text { (Entidade Nacional dos Estudantes } \\
\text { de Biologia), pesquisadores da } \\
\text { UFV (Universidade Federal de } \\
\text { Viçosa) e Levante Popular da } \\
\text { Juventude. }\end{array}$ \\
\hline $\begin{array}{l}\text { Reuniões com as comunidades } \\
\text { atingidas pelo mineroduto da } \\
\text { Ferrous, em Viçosa, Paula } \\
\text { Cândido, Ervália, e Coimbra, } \\
\text { realizada entre os meses de } \\
\text { fevereiro a julho de } 2012 .\end{array}$ & $\begin{array}{l}\text { As reuniões tiveram o intento de levar } \\
\text { informações sobre o mineroduto } \\
\text { da Ferrous para as comunidades } \\
\text { atingidas pelo o empreendimento, } \\
\text { bem como retirar dúvidas sobre a } \\
\text { implantação do mineroduto. }\end{array}$ & $\begin{array}{l}\text { MAB, PACAB, ENEBio, } \\
\text { Associação dos Moradores do } \\
\text { Bairro Santa Clara, Associação } \\
\text { dos Moradores do Bairro Palmital, } \\
\text { Levante Popular da Juventude, } \\
\text { MST, AGB (Associação dos } \\
\text { Geógrafos Brasileiros), membros } \\
\text { da Igreja Católica e pesquisadores } \\
\text { da UFV. }\end{array}$ \\
\hline
\end{tabular}


Criação da "Campanha pelas Águas e Contra o Mineroduto da Ferrous", em abril de 2012.
A campanha é a manifestação de um grupo de pessoas, composto por atingidos e representantes dos movimentos sociais, e tem por objetivo criar espaços para discutir e informar aos atingidos e à comunidade em geral sobre o mineroduto e, ainda, criar mecanismos de resistência contra tal empreendimento.

MAB, Associação de Moradores do Palmital, Associação de Moradores do Bairro Santa Clara, Paróquia Nossa Senhora de Fátima, PACAB, ENEBIO, AGB, Levante Popular da Juventude, ABEEF (Associação Brasileira de Estudantes de Engenharia Florestal), FEAB (Federação dos Estudantes de Agronomia do Brasil), ANECS (Articulação Nacional dos Estudantes de Ciências Sociais).

Audiência pública promovida pelo Ministério Público do Estado de Minas Gerais (MPMG), realizada em julho de 2012.

Debate sobre a criação da Área
de Proteção Ambiental (APA)
do ribeirão São Bartolomeu, em
agosto de 2013 .

Manifestação perante a Ministra da Secretaria de Direitos Humanos da Presidência da República, Maria do Rosário Nunes, em março de 2013.

Seminário realizado em fevereiro
de 2014, no município de Paula
Cândido.
Realização da mesa-debate na
UFV: "Mineroduto em Viçosa!
Impactos na UFV?" em maio
de 2014.

Evento realizado para que a comunidade atingida, direta e indiretamente, pelo mineroduto relatasse os impactos ambientais e sociais que estão enfrentando frente à implementação do mineroduto da Ferrous.

Tendo em vista diversos problemas com a falta de água na cidade de Viçosa, foi realizada uma reunião com o intento de impulsionar as discussões sobre a APA no ribeirão São Bartolomeu, uma vez que o mineroduto da Ferrous tende a passar nas nascentes deste ribeirão. Em visita à cidade, para inaugurar o ano letivo da Universidade Federal de Viçosa, a Ministra da Secretaria de Direitos Humanos da Presidência foi surpreendida por cartazes, encenações e palavras de ordem contra o Mineroduto da Ferrous.

Teve por objetivo traçar as metas de ação para 2014 contra a empresa Ferrous.

Esse evento teve como objetivo levar a discussão sobre os impactos do mineroduto para a comunidade universitária.
Estudantes da UFV.

Manifestantes da Campanha pelas Águas Contra o Mineroduto da Ferrous.

Campanha pelas Águas Contra o Mineroduto da Ferrous, PACAB e atingidos do município de Paula Cândido.

Campanha pelas Águas Contra o
Mineroduto da Ferrous, PACAB, pesquisadores e representantes da Universidade Federal de Viçosa 


\begin{tabular}{|c|c|c|}
\hline $\begin{array}{l}\text { "I Torneio de Truco Contra o } \\
\text { Mineroduto" acontecido em } \\
\text { outubro de 2014, na zona rural } \\
\text { de Paula Cândido. }\end{array}$ & $\begin{array}{l}\text { Um evento simbólico que marcou } \\
\text { mais um ponto de resistência } \\
\text { contra o mineroduto. Neste torneio, } \\
\text { ocorreram jogos, músicas e faixas de } \\
\text { protestos contra o empreendimento } \\
\text { da Ferrous. }\end{array}$ & $\begin{array}{l}\text { Campanha pelas Águas Contra o } \\
\text { Mineroduto da Ferrous, PACAB } \\
\text { e atingidos do município de Paula } \\
\text { Cândido. }\end{array}$ \\
\hline $\begin{array}{l}\text { Passeata no município de Paula } \\
\text { Candido, realizada em dezembro } \\
\text { de } 2014 .\end{array}$ & $\begin{array}{l}\text { O evento tinha por intuito pressionar } \\
\text { a prefeitura municipal a cancelar } \\
\text { as licenças de passagem do } \\
\text { empreendimento no município. }\end{array}$ & $\begin{array}{l}\text { Campanha pelas Águas Contra o } \\
\text { Mineroduto da Ferrous, PACAB } \\
\text { e atingidos do município de Paula } \\
\text { Cândido. }\end{array}$ \\
\hline $\begin{array}{l}\text { Passeata e panfletagem no ato } \\
\text { "Em defesa das águas", em abril } \\
\text { de } 2015 \text {, na cidade de Viçosa. }\end{array}$ & $\begin{array}{l}\text { O ato, que fez parte da Semana } \\
\text { "Em defesa das águas", objetivou } \\
\text { apresentar, à comunidade viçosense, } \\
\text { os impactos no abastecimento } \\
\text { público da especulação imobiliária } \\
\text { e na instalação do mineroduto da } \\
\text { Ferrous em Viçosa. }\end{array}$ & $\begin{array}{l}\text { Grupos de reflexão das Paróquias } \\
\text { de Viçosa, Campanha Pelas Águas, } \\
\text { NACAB, MAB, PACAB e Levante } \\
\text { Popular da Juventude. }\end{array}$ \\
\hline $\begin{array}{l}\text { Voto do conselho universitário } \\
\text { da UFV contra o mineroduto, em } \\
\text { março de } 2015 \text {. }\end{array}$ & $\begin{array}{l}\text { AUFV assumiu uma posição [oficial] } \\
\text { contrária à passagem do mineroduto } \\
\text { da Ferrous. Em reunião presidida } \\
\text { pela reitora da Universidade, o } \\
\text { Conselho Universitário (Consu) } \\
\text { desta instiruição declarou que } \\
\text { a posição da Universidade foi } \\
\text { embasada no parecer da Comissão } \\
\text { Técnica responsável por discutir } \\
\text { a instalação do mineroduto da } \\
\text { Ferrous. }\end{array}$ & Universidade Federal de Viçosa. \\
\hline
\end{tabular}

Fonte: Organização dos autores, 2015 
Figura 2 - Ações de resistência contra o mineroduto da Ferrous na microrregião de Viçosa

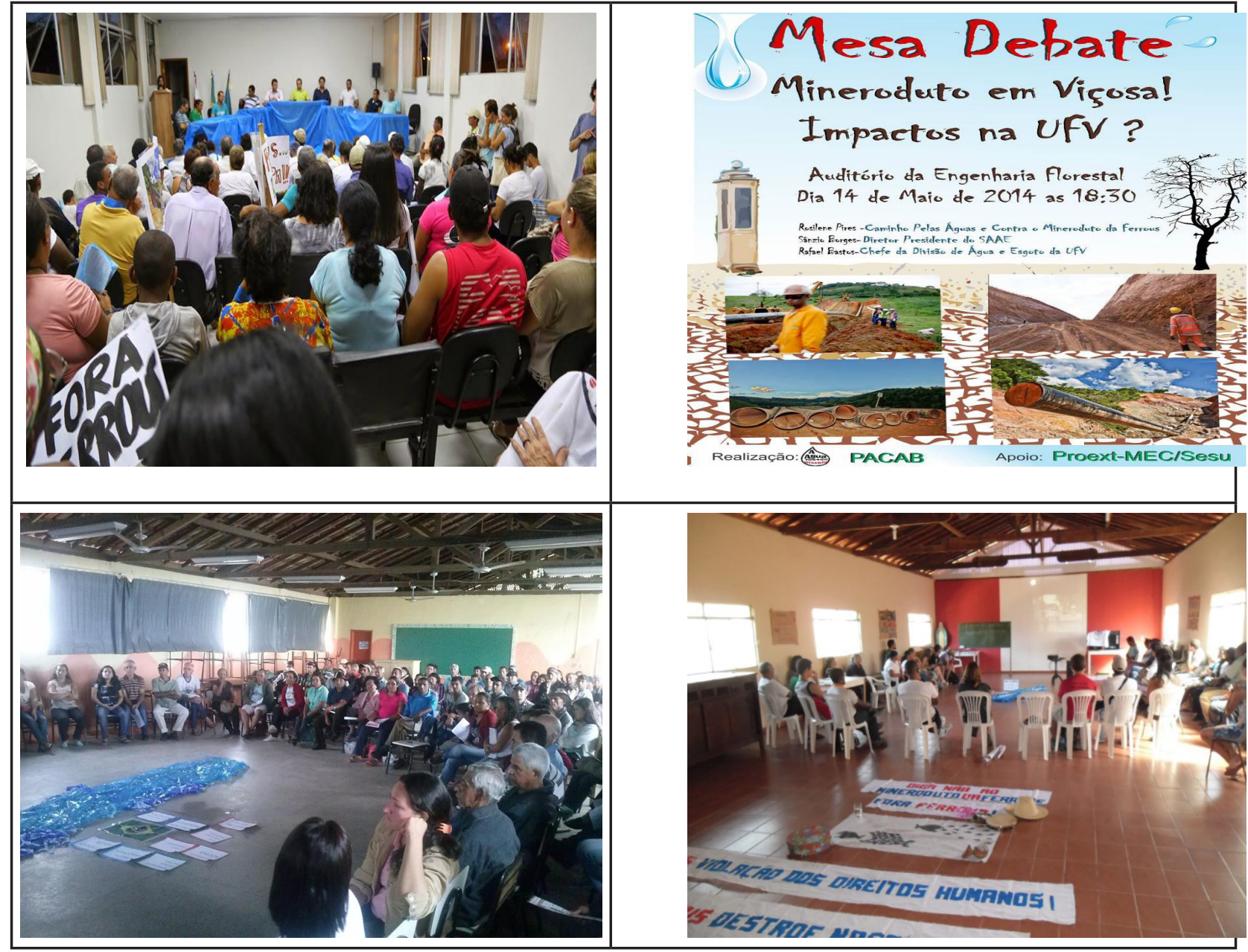

Fonte: Acervo do PACAB, 2014-2015

Ao analisar a relação de poder dos atingidos, percebe-se que estes apresentam uma posição de dominados diante da empresa Ferrous. Mesmo que resistam contra a implantação do empreendimento, eles têm um capital social diante do campo de conflitos no qual estão envolvidos, mas essas ações de resistência dos atingidos só estão fazendo com que o empreendedor tenha alguns obstáculos para que o empreendimento seja construído, uma vez que o empreendedor possui maior poder simbólico e econômico diante dos demais atores sociais envolvidos em tal conflito.

Empresa mineradora Ferrous Ressources do Brasil S/A: para executar o projeto do mineroduto, o empreendedor utiliza várias estratégias para que o empreendimento saia do papel. Primeiramente, buscou o apoio do governador de Minas Gerais e o mesmo retribuiu com a entrega de um Decreto de Utilidade Pública do Mineroduto da Ferrous, antes mesmo do empreendedor ter recebido a licença prévia do IBAMA.

Em segundo lugar, as audiências públicas promovidas pelo empreendedor, e que fizeram parte do processo de licenciamento, foram apresentadas com informações que as pessoas presentes na audiência já sabiam e as informações que o público queriam saber, como impactos, indenizações, área atingida, benefícios do empreendimento, dentre outras, não foram abordadas. Esta tática, geralmente, é utilizada pelos empreendedores para não ter muito tempo de responder às dúvidas das pessoas e para não assumir os pontos negativos do empreendimento. Dessa forma, o empreendedor passa a visão de que o empreendimento 
é algo bom para todos.

De acordo com Bronz (2011, p. 38), "as audiências públicas são os principais 'ritos' cerimoniais dos procedimentos de licenciamento ambiental". Isto é, nas audiências, os consultores do EIA do empreendimento apresentam várias informações sobre as comunidades atingidas com o intuito de gastar tempo para não apresentar as informações tidas como importante para os atingidos (impactos, indenizações, área atingida, entre outros) e para não responder às perguntas realizadas pelos mesmos. Nesta perspectiva, pode-se dizer que a Ferrous também utilizou esse mecanismo para não informar aos atingidos sobre os assuntos que os interessavam.

Em terceiro lugar, a Ferrous utiliza agentes sociais para demonstrar para a sociedade em geral que ela tem um relacionamento direto e contínuo com as comunidades atingidas por tal empreendimento, mas, na prática, isso não acontece.

Em dezembro de 2012, a Ferrous divulgou notas na imprensa e contatou os proprietários informando que a execução do projeto do mineroduto seria adiada e somente implantada a partir de 2016. O motivo deste adiamento seria em razão da baixa do valor do minério de ferro e, com isso, não havia justificativa para o investimento na construção do mineroduto até o ano supracitado, além do fato de que a mina não estava produzindo a quantidade de minério planejada. Além disso, o empreendedor deixou claro, nos seus discursos, que não estava desistindo do mineroduto e que, apesar de ter adiado o início das obras, a empresa trabalharia arduamente no processo de licenciamento ambiental, isto é, do recebimento da Licença de Instalação.

Ao analisar a relação de poder deste ator, percebe-se que ele tem um poder simbólico, conforme Bourdieu (1998) apresenta na sua teoria, o qual representa a figura de dominante diante deste conflito ambiental.

O Estado: representado pelos seus órgãos reguladores configura-se entre os atores envolvidos. $\mathrm{Na}$ dinâmica dos conflitos, o Estado vem se posicionando de maneira instável, isto é, ora se encontra a favor da construção do mineroduto da Ferrous, ora contra tal obra. Essa posição contrária foi ganhando destaque, no início de junho de 2012, quando o Poder Público
Municipal, representado pelo promotor de Justiça da comarca de Viçosa, começou a ouvir os depoimentos dos atingidos e solicitou à promotoria do Estado de Minas Gerais que realizasse uma audiência pública em Viçosa para ouvir as comunidades atingidas sobre os impactos sociais ocasionados pelo mineroduto da Ferrous. Essa audiência foi realizada no dia 12 de julho de 2012, no município de Viçosa. Na ocasião, vários atingidos relataram os impactos e a violação dos Direitos Humanos que vinham enfrentando com a implantação do mineroduto da Ferrous. Na audiência, o promotor afirmou que:

A Ferrous apresentou um laudo sobre a instalação do mineroduto, o qual foi comparado com a perícia feita pela CEAT, e várias incongruências foram observadas. Uma delas diz respeito ao consumo humano de água. De acordo com a Ferrous Ressources, não há consumo na jusante dos cursos que serão atravessados pelo mineroduto, informação que não corresponde à perícia feita pela CEAT (BLOG VIÇOSA CIDADE ABERTA, julho de 2012).

Após dois meses da audiência, foi realizada uma entrevista com o promotor e ele relatou que, até aquele momento, não havia ocorrido uma mediação entre o Ministério Público e o empreendedor, pois ele acreditava que:

A mediação pelo Ministério Público poderia ser alcançada a partir da celebração de um Termo de Ajustamento de Conduta, onde a empresa se comprometesse, desde que identificasse as irregularidades, a regularizar essas questões para a instalação ou não da sua obra do mineroduto aqui no município (Relato da entrevista com o promotor de Justiça de Viçosa, 2012).

Depois disso, propriamente no início de junho de 2013, o promotor encaminhou uma carta ao representante do $\mathrm{PACAB}$, informando que o processo com a Ferrous tinha sido arquivado em função de um Termo de Ajustamento de Conduta (TAC) firmado 
entre o Ministério Público do município de Viçosa (representado pelo promotor) e a empresa Ferrous Ressources. Este termo assinalava que, antes da Ferrous iniciar a construção do mineroduto, a empresa teria que fazer um estudo hídrico no município de Viçosa e apresentar soluções para os possíveis impactos sobre os recursos hídricos. Até meados de 2015, esses estudos ainda não haviam sido concluídos ou, se foram, não haviam sido apresentados às comunidades atingidas ou aos municípios que serão impactados.

Diante dessa discussão, percebe-se que o Estado, representado pelo poder público de Viçosa, inicialmente, ocupava um lugar de dominante diante da Ferrous (dominada), entretanto, de uma hora para outra, a situação se inverteu e a Ferrous novamente passou a ser dominante e o Estado dominado. Com certeza, o poder simbólico e econômico do empreendedor se sobressaiu nesse caso.

Prefeitura Municipal de Viçosa e Câmara dos Vereadores de Viçosa (representando o Estado também): estes órgãos, que têm o papel de investigar os impactos que este empreendimento está trazendo e trará para o município e de questionar o modo como a empresa Ferrous vem tratando os proprietários que estão no trajeto de passagem do mineroduto, não estão questionando a empresa de forma a atender a população atingida.

Desde o momento em que a população viçosense ficou sabendo do projeto do mineroduto, só existia um vereador que estava junto à comunidade e aos atingidos desde o início da resistência à implantação de tal empreendimento. Porém, no final de 2012, a Câmara dos Vereadores de Viçosa pronunciouse contra a implantação desse empreendimento no município, por meio de uma moção de repúdio (013/2012) à passagem do mineroduto da Ferrous no município, o que pode sugerir que a maioria dos vereadores estaria contrária ao empreendimento. Nas eleições daquele mesmo ano, o empreendimento virou foco de discussões nos debates.

Cabe destacar que o prefeito municipal de Viçosa, na ocasião do início das mobilizações contrárias ao empreendimento, foi reeleito em 2012, e que era alinhado ao discurso das mineradoras e pertencia ao grupo, no Estado de Minas Gerais, que apoiava esses empreendimentos. Portanto, era um político favorável à passagem do mineroduto e, em seus depoimentos, era comum dizer que o mineroduto da Ferrous não traria nenhum impacto à Viçosa e que também não impactaria no abastecimento de água do município.

Em 2014, um novo fato trouxe uma reviravolta ao caso. Com o falecimento do então prefeito, depois de um infarto, o vice-prefeito assumiu em outubro de $2014 \mathrm{e}$ uma das primeiras medidas foi revogar todos os atos administrativos e de autorização de implantação do mineroduto em Viçosa. Como argumento para esse ato o novo prefeito afirmou que: "O chefe do executivo, em seu decreto, considerou, dentre outros, princípio da autotutela e o interesse público revelado na instalação do mineroduto que se pretendia levar a cabo em solo viçosense, consubstanciado nas inúmeras interferências no meio ambiente necessárias à implantação do empreendimento" (JORNAL FOLHA DA MATA, 2014, n. 2.381, p. 1).

Diante dos fatos ocorridos, é possível perceber que a Prefeitura Municipal e a Câmara dos Vereadores de Viçosa apresentavam-se como dominadas diante da empresa Ferrous, no entanto, a partir de outubro de 2014, essa situação se inverteu, pelo menos até outubro de 2015.

Conselho Municipal de Defesa e Conservação do MeioAmbiente (CODEMA) do município de Viçosa: além da prefeitura, em 2014, o CODEMA também se posicionou contrário à passagem do mineroduto, por acreditar que o EIA do empreendimento subestimou os impactos que o empreendimento traria nas bacias que abastecem o ribeirão São Bartolomeu, o Rio Turvo Sujo e o Rio Turvo Limpo (OLIVEIRA, 2014). Desta forma, é possível afirmar que o CODEMA apresentase como um dos atores sociais que também está ocupando a posição de dominador diante da empresa Ferrous, ressaltando-se que esta posição foi assumida a partir do ano de 2014.

Movimentos sociais, as Organizações Não Governamentais (ONG's), a Igreja Católica e os pesquisadores: representados pelo $\mathrm{MAB}, \mathrm{PACAB}$, ENEBio, MST, AGB, NACAB, Levante Popular da Juventude, Associação dos Moradores do Bairro Santa 
Clara, Associação dos Moradores do Bairro Palmital (comunidade que, possivelmente, será atingida) e Paróquia Nossa Senhora de Fátima de Viçosa. Estes atores se posicionam contra a instalação do mineroduto, pois a implantação deste empreendimento está trazendo diversos conflitos para a comunidade e vários impactos ao meio ambiente.

Nesse sentido, o primeiro argumento contrário desses atores refere-se à falta de parâmetro do empreendedor para realizar a negociação das indenizações com os proprietários das terras e, ainda, que a quantia paga pelas terras a serem desapropriadas está abaixo do valor real do imóvel. Observando os dados levantados, é possível perceber que o mineroduto passará em locais de elevado valor afetivo para os proprietários das terras, no entanto, o que se percebe é que estes valores simbólicos não estão sendo contabilizados no processo de indenização. Tais valores inflamariam ainda mais a questão das indenizações deixando mais sensíveis os debates.

Já o segundo argumento contrário relaciona-se ao problema de que a falta de água, que vem ocorrendo nos bairros altos de Viçosa, poderá se alastrar ainda mais, caso haja a implantação do mineroduto nesse município. Nesse sentido, esses atores propõem que o mineroduto mude o seu trajeto, não passando, assim, nas nascentes do ribeirão São Bartolomeu, uma vez que esse ribeirão abastece, com água, 50\% da cidade de Viçosa e 100\% da Universidade Federal de Viçosa. Além disso, o movimento como um todo sugere medidas mitigadoras de impactos sobre o abastecimento d'água do município, como: a imediata criação da Área de Proteção Ambiental (APA) do ribeirão São Bartolomeu, a construção de mais duas ou três estações de tratamento com redes interligadas ao atual sistema, a construção de aquedutos para abastecimento dessas estações, de modo que não haja grandes preocupações com a água (JORNAL FOLHA DA MATA, 2012).

$\mathrm{Na}$ análise da relação de poder destes atores, percebe-se que eles são dominados diante do poder simbólico do empreendedor. É importante salientar também que, apesar deste fato, os representantes dos movimentos sociais, das Organizações Não Governamentais (ONG's), da Igreja Católica e dos pesquisadores foram atores importantes nas mobilizações contrárias ao mineroduto, contribuindo, assim, para que as obras não fossem iniciadas.

\section{CONSIDERAÇÕES FINAIS}

Diante das discussões realizadas ficou explícito que a expectativa de implantação do mineroduto da Ferrous ocasionou o conflito ambiental, sobretudo, na microrregião de Viçosa-MG. Ademais, a construção deste empreendimento segue o contexto de desenvolvimento econômico insustentável e da exploração do território, ou seja, o território será usado de forma a incrementar os lucros do empreendedor, trazendo pouco desenvolvimento para as regiões e deixando grandes impactos ambientais e sociais.

Pode-se constatar, ainda, que o Estado (representado pelo Poder Público do Município de Viçosa, pela Prefeitura Municipal de Viçosa, pela Câmara dos Vereadores de Viçosa e pelo CODEMA) não vinha sendo efetivo no papel de mediação e gestão dos conflitos no município, se colocando do lado do empreendedor e deixando de ir ao encontro dos direitos das comunidades atingidas. Somente a partir de outubro de 2014, esse cenário foi alterado, ou seja, esses atores passam a ser contra a implantação do mineroduto da Ferrous.

Também foi possível verificar que o empreendedor possui um poder simbólico diante dos demais atores (atingidos pelo mineroduto, representantes do Estado, dos movimentos sociais, ONGs e Igreja). Isto é, a Ferrous ocupa a posição de dominadora diante dos atores sociais envolvidos, e os demais, por sua vez, ocupam a posição de dominados. Portanto, no caso do mineroduto, há uma assimetria de poder entre os atores sociais envolvidos no conflito ambiental.

Por fim, em relação às ações de resistências contra a implantação do mineroduto da Ferrous na microrregião de Viçosa, é possível notar que tais atos estão sendo importantes para divulgar o caso deste empreendimento, o qual traz e trará impactos aos atingidos e à sociedade, bem como ao meio ambiente. Acredita-se que as ações de resistência, mapeadas no Quadro 2, trazem sinais de que a construção e o funcionamento do mineroduto não é algo bom para a sociedade. Além disso, acredita-se que essas 
manifestações contra o mineroduto vêm colhendo alguns frutos, como o posicionamento contrário a este empreendimento pela Prefeitura Municipal de Viçosa, Câmara dos Vereadores de Viçosa, Universidade Federal de Viçosa e CODEMA. Nesse sentido, observa-se que há uma tendência de que a empresa Ferrous mude a sua posição de dominadora, passando a ser dominada pelos atores sociais contrários à implantação do mineroduto.

Portanto, este trabalho demonstrou que a empresa Ferrous, detentora de alto poder econômico e simbólico, assume o papel de dominadora no conflito. Por outro lado, os atingidos e os movimentos sociais contrários à construção do empreendimento, por vezes, estão no papel de dominados, restandolhes articular estratégias de resistência, conforme mostrou os dados no Quadro 2, para adiar/barrar a construção do mineroduto. O Estado, por sua vez, assume diferentes papéis no contexto, demonstrando, com isso, fragilidade na intermediação e gestão do conflito instaurado pelo mineroduto da Ferrous, principalmente, na microrregião de Viçosa-MG.

\section{REFERÊNCIAS}

ACSELRAD, Henri. As práticas espaciais e o campo dos conflitos ambientais. Conflitos ambientais no Brasil. Rio de Janeiro: Relume-Dumará, 2004, p.1335.

ARAÚJO, Sérgio Silva. Conflitos sócio-ambientais relacionados ao uso da água outorgada da bacia hidrográfica do Rio Japaratuba-SE. 2008. 117f. Dissertação (Mestrado em Desenvolvimento e Meio Ambiente) - Universidade Federal de Sergipe, Sergipe.

BLOG VIÇOSA CIDADE ABERTA. Audiência Pública do MPMG: mineroduto da Ferrous. Disponível em: <http://vicosacidadeaberta.blogspot.com. br/2012/07/audiencia-publica-do-mpmg-minerodutoda.html?q=mineroduto $>$. Acesso em: 10 jun. 2013.

BOURDIEU, Pierre. O poder simbólico. Rio de Janeiro: Bertrand Brasil, 1998.
BRANDT Meio Ambiente. Relatório de Impactos Ambientais: Mineroduto Ferrous Minas Gerais, Rio de Janeiro e Espírito Santo. Julho, 2010.

BREDARIOL, Celso Simões. O aprendizado da negociação em conflitos ambientais. In: II Encontro da ANPPAS, Indaiatuba, SP, Maio 2004. Disponível em: <http://www.anppas.org.br/encontro_anual/ encontro2/ >. Acesso em: 08 out. 2015.

BRONZ, Deborah. Empreendimentos e empreendedores: formas de gestão, classificações e conflitos a partir do licenciamento ambiental. 2011. 504f. Tese (Doutorado em Antropologia Social) - Universidade Federal do Rio de Janeiro, Museu Nacional, Rio de Janeiro.

BRUMER, Anita; SANTOS, José Vicente Tavares dos. Estudos agrários no Brasil: modernização, violência e lutas sociais (desenvolvimento e limites da Sociologia Rural no final do século XX). Revista Nera, v. 9, n. 9, p. 49-72, 2006.

CASTRO, Armando; OTÁVIO, Luis. Diagnóstico Ambiental do Meio Socioeconômico. Estudo de Impactos Ambientais do Mineroduto Ferrous. 2010. Parte IV.

ELIAS, Norbert. Introdução à Sociologia. Lisboa: Edições 70, 1969.

FRANCO, Maria Amélia Santoro. Pedagogia da Pesquisa-Ação. Educação e Pesquisa, São Paulo, v. 31, n. 3, p. 483-502, 2005.

JORNAL FOLHA DA MATA. Não ao Mineroduto. Viçosa, 20/11/2014, n. 2.381, p. 1. Ano LI, p. 1.

JORNAL FOLHA DA MATA. Assembleia Popular "Água x Mineroduto” em Viçosa. Viçosa, p. 10, 26/04/2012, p. 10.

JORNAL TRIBUNA LIVRE. Produtores se reúnem contra mineroduto. Viçosa, 24/06/2011, p. 17.

NASCIMENTO, Daniel Trento; BURSZTYN, Maria 
Augusta Almeida. Análise de conflitos socioambientais: atividades minerárias em comunidades rurais e Áreas de Proteção Ambiental (APA). Desenvolvimento e Meio Ambiente, n. 22, p. 62-82, 2010. DOI: http:// dx.doi.org/10.5380/dma.v22i1.20348

PEREIRA, Doralice Barros; PENIDO, Marina de Oliveira. Conflitos em empreendimento hidrelétricos: possibilidades e impossibilidades do (des)envolvimento social. In: ZHOURI, Andréa; LASCHEFSKI, Klemens (orgs.). Desenvolvimento e conflitos ambientais. Belo Horizonte: Editora UFMG, 2010, p. 250-275.

OLIVEIRA, Marcelo L. Romarco. Mineração e conflito ambiental: o caso do mineroduto da Ferrous na zona da mata do estado de Minas Gerais-Brasil. Revista de Geografia, Recife, UFPE, v. 31, p. 113129, 2014.

SANTOS, Pollyana Martins. Licenciamento, conflito e justiça ambiental: uma análise a partir dos coletivos em Rede na Zona da Mata Mineira. 2012. 169f. Dissertação (Mestrado em Economia Doméstica) Universidade Federal de Viçosa, Viçosa.

VARGAS, Glória Maria. Conflitos sociais e sócio-ambientais: proposta de um marco teórico e metodológico. Sociedade e natureza, Uberlândia, n. 19, p. 191-203, 2007.

VIANA, Cristine. Conflitos socioambientais do Projeto de Integração do Rio São Francisco. 2005. 166f. Dissertação (Mestrado em Desenvolvimento Sustentável) - Universidade de Brasília, Brasília.

WEBER, Max. Economia e sociedade: fundamentos da sociologia compreensiva. Brasília: editora Universidade de Brasília, 2000. 